\title{
A STUDY OF KNOWLEDGE AND PRACTICE ON INTESTINAL HELMINTHIASIS AMONG RURAL TRIBAL MOTHERS OF UNDER FIVE CHILDREN IN MOHANPUR BLOCK, WEST DISTRICT OF TRIPURA: A NORTH EASTERN STATE OF INDIA.
}

\author{
Amar Tripura ${ }^{1}$, Taranga Reang ${ }^{2}$, Kaushik Tripura ${ }^{3}$, Arundhuti Roy ${ }^{4}$
}

\section{HOW TO CITE THIS ARTICLE:}

Amar Tripura, Taranga Reang, Kaushik Tripura, Arundhuti Roy. "A study of knowledge and practice on intestinal helminthiasis among rural tribal mothers of under five children in Mohanpur block, west district of Tripura: a north eastern state of India". Journal of Evolution of Medical and Dental Sciences 2013; Vol2, Issue 47, November 25; Page: 9081-9087.

ABSTRACT: The overall prevalence of helminths infection in school age children in India is about $50 \%$ in Urban and 68\% in rural area. Tribal populations especially the children living under low socio-economic conditions in the rural villages where poor sanitary system exist are at higher risk of worm infestation. Objectives: To assess mother's knowledge and practice towards worm infection of their under five children. METHODS: A cross sectional study was conducted among 117 mothers of under five children who were selected through systematic random sampling method in the year 2012 and face to face interview was performed using semi-structured questionnaire in the rural village under Mohanpur Rural Development block, West district of Tripura. RESULTS: 19\%, 26.80\% and $2.6 \%$ of respondent reported of round worm, thread worms and tape worms respectively. $23 \%$, $19.60 \%, 19.60 \%, 23 \%$ and $14.80 \%$ reported of pain abdomen, pain abdomen and itching, perianal itching, vomiting and worms in stool or worms coming through nose respectively. About $51.60 \%$ of the respondents were unable to describe even a single helminthic infection. There were significant associations observed between helminthic infection and use of types of latrine $(p=0.000)$, hand washing after defecation $(p=0.000)$, regular hand wash before meals $(p=0.000)$ and regular use of foot wears $(p=0.000)$. CONCLUSIONS: Most of the respondents being literate, intestinal helminthiasis was considered harmless and normal phenomenon. A wrong idea also prevailed that eating sugary things caused worm infestation. Other risk factors that existed were lack of hygienic behavior about washing hands \& using insanitary latrines. Awareness generation and behavior change programs were needed in this group of population.

KEY WORDS: Knowledge, Practice, worm infection, Mothers of under five children.

INTRODUCTION: More than 1 billion people are parasitized by soil-transmitted helminths (STHs), namely Ascaris lumbricoides, Trichuris trichiura and the hookworms (Ancylostoma duodenale and Necator americanus).(1-4). The overall prevalence of helminthes infection in school age children in India is about 50\% in Urban and 68\% in rural area.(5) The World Health Organization (WHO), 2008 estimates that infection with round worm (Ascaris lumbricoides), whipworm (Trichuris trichiura) and hookworms (Ancylostoma duodenale and Necator americanus) affect approximately 250 million, 46 million and 151 million people, respectively (6) Thus, worm infestation as a public health problem needs immediate attention from policy makers in India and other South Asian countries. (7) Most helminths infections, if left untreated, result in multi-year, chronic inflammatory disorders that cause both concurrent and delayed-onset pathology to the afflicted human host, (8-10) it is now appreciated that chronic helminths infections are also linked to more insidious persistent health 


\section{ORIGINAL ARTICLE}

conditions such as anemia, growth stunting, and protein-calorie under nutrition, fatigue, and poor cognitive development (9). In general rural areas are expected to have higher worm load, than urban area, because of the preponderance of those factors that perpetuates the continued existence of the worm, such as poverty, poor environmental hygiene, and complete absence of municipal services.(1113) Poor environmental sanitation in communities, improper disposal of waste, like human feces and other organic wastes, gross environmental pollution with agrochemical and industrial waste and the steady contamination with water and air.(14) Villagers and their children are living under the risk environments and are highly exposed to intestinal helminths infection throughout their life, further a wrong idea about the spread of worm infection may leave children openly vulnerable. Tribal populations especially the children living under low socio-economic conditions in the rural villages where poor sanitary system exist are at higher risk of worm infestation.

MATERIAL AND METHODS: A cross-sectional study was conducted among the tribal mothers in the rural village under Mohanpur Rural Development Block of West district, Tripura during the period of February to march 2012. The total population in this block was about 1 lakhs and 25kms away from capital city of Agartala. The sample size (n)=4pq/L2 $=117$ was calculated where $p=80 \%,(15)$ $\mathrm{q}=20 \%, \mathrm{~L}=10 \%$ of $\mathrm{p}=8$ with a non response rate of $20 \%$ at $95 \%$ confidence and $5 \%$ level of significance. Sick mothers and who could not be contacted on two successive visits were excluded. A structured and pre tested interview schedule was used for data collection. One hundred seventeen (117) mothers of under five children were selected randomly from the list of 554 (five hundred fifty four), from 12 (twelve) Anganwadi centers out of the three rural villages using systematic random sampling. The sampling interval (k) as 5(five) was calculated and the fourth no of house (mother of under five) out of five was randomly selected and came to be the first house in the study sample. The next consecutive houses were selected as 9, 14, and 19 and so on till the sample size was achieved. Mothers were interviewed in the local language after obtaining a verbal consent, and the statements recorded in a structured and pretested interview schedule. Local Accredited Social Health Activists (ASHA) and Anganwadi workers (AWW) were informed and their help was taken to identify the families with under- five years of age children during the full course of data collection. Ethical clearance from the Institutional Ethics Committee of Agartala Government Medical College was obtained before conducting the study. Strict confidentiality was maintained. Data were analyzed in terms of percentage and chi-square test using Epi-info version 6.0. and Microsoft Excel 2007.

RESULTS: The present study was conducted among 117 tribal mothers in selected villages under Mohanpur block of West district of Tripura. Among which 42.7\% were in the age group of 26-30 years, followed by $20-25$ years (34.2\%), 31-35 years (18.8\%) and 36-40years (4.3\%). 98.3\% were Hindu and remaining 1.7\% Christian. $40.2 \%$ were in the per month family income group of $\leq$ Rs.5000/-, another $40.2 \%$ had family income Rs.5, 000/- to Rs.10, 000/-pm, 11.1\% had family income of Rs. 10, 000/- to Rs.15000/-pm, 4.3\% had family income of Rs. 15000/- to Rs.20000/-pm, $1.7 \%$ had family income of Rs. $20000 /-$ to Rs. $25,000 /-\mathrm{pm}$ and remaining $2.5 \%$ had family income of $\geq$ Rs. 25000/-pm.

Among the respondents $58.1 \%$ and $41.9 \%$ considered worms to be harmful and harmless respectively. It was revealed that $19 \%, 26.80 \%$ and $2.6 \%$ of respondent reported of knowing of round worm, thread worms and tape worms respectively. 23\%, 19.60\%, 19.60\%, 23\% and 14.80\% 


\section{ORIGINAL ARTICLE}

reported of pain abdomen, pain abdomen and itching, perianal itching, vomiting and worms in stool or worms coming through nose respectively as the signs and symptoms of worm infestations. 1.70\%, $10.30 \%, 52.10 \%, 10.30 \%$ and $11.10 \%$ reported of eating food contaminated with soil, eating with unclean hands, eating sugary foods, eating with unwashed hands and sugary foods and eating meats and sugary foods respectively were the cause of worm infestation. Among the participants 23.9\% reported sugar, $19.6 \%$ human feces, $12.8 \%$ soil and $6.8 \%$ meat to be the source of worm infestations (table1). 64.96\% mothers reported hand washing before eating and feedings, 58.12\% reported hand washing after defecation of self and children, $57.27 \%$ regular use of foot wears by self and children, $83 \%$ reported of maintained food hygiene and $40.17 \%$ uses sanitary latrine to prevent worm infection of their children. Thirty six (40\%) mothers consulted private practitioners, 31\% attended government hospital $18 \%$ did home remedies and $7 \%$ went for over the counter medication for treatment of worm infections of their children (table2).

There were significant associations observed between worms infection and use of types of latrine $(p=0.000)$, hand washing after defecation $(\mathrm{p}=0.000)$, regular hand wash before meals $(p=0.000)$ and regular use of foot wears $(p=0.000)$ (table3). 59.80\% treated with anthelminthic drugs at least once during the past one year (fig 1).

DISCUSSION: The present study was conducted in a rural tribal population of Mohanpur block of west district of Tripura. A total of 117 rural tribal mothers were selected after fulfilling the selection criteria. Majorities of mothers were Hindu, in the age group of 26-30 years and within income group Rs.10, 000/-pm. Among the respondents 58.1\% considered worm infection as harmful. A study conducted in Qena city reported 89.3\% considered worm as harmful.(16) The difference might be due to study setting. Another study from Abidijan, Cote d'Ivore all the respondents considered worms as harmful.(17) Almost similar results was reported from a study in Nepal.(18) Among the study population $23 \%, 19.60 \%, 19.60 \%, 23 \%$ and $14.80 \%$ reported of pain abdomen, pain abdomen and itching, perianal itching, vomiting and worms in stool or worms coming through nose respectively were the signs and symptoms of worm infection. An almost similar results were reported by Acka CA et al (2010).(17) Majority of the respondents lacked adequate knowledge and it was almost similar to previous reports regarding helminthic infections.(19-21) Majority of the mothers whose children were infected with intestinal helminths had either illiterate or primary school education level, and this might be one of factors that attributed to inability to associate worm's infection with the symptoms or being unaware of the preventive measures. The above observation was common and similar observations have been reported in other countries. ${ }^{19,22)}$ Less than half $(31 \%)$ of mothers sought treatment from hospital and this could be due to illiteracy on worm's infection which in turn might have greatly attributed to the lack of knowledge on anthelminthics. Geerts S et al (2001)(23) and Cioli D (2000) (24) reported almost similar results. Majority of respondents in the present study washed their hands and also for their children before eating and after defecation. Almost similar observations were reported in a study in Murhu block where mothers used soap and water for hand wash after defecation.(25) The practiced observed by mothers were higher compared to that observed from Ichhawar (22\%) and Astha block (54\%) in Rural Madhya Pradesh.(26) Further, 64.91\% reported hand washing before eating. It was higher compared to findings from Ichhawar (8\%) and 22\% in Astha in Rural Madhya Pradesh.(26) The difference might be due difference in level of education and socioeconomic status between study subjects. The present study showed that $40 \%$ 


\section{ORIGINAL ARTICLE}

of mothers consulted private practitioners and 31\% attended government hospitals for the worms' treatment of their children whereas in a study in Kep District, Kingdom of Cambodia 55.6\% of mothers sought Private medical treatment and 22.2\% sought Public Medical Services.(27) The use of sanitary latrine was significantly associated to be protective from worm infection compared to those using insanitary latrine ( $p=0.000)$. A similar observation was reported from a study in Gurez Valley.(28) The hand washing practiced after defecation was protective for worm infestation $(\mathrm{p}=$ 0.000). Almost similar results were reported from the studies in selected blocks of Uttar Pradesh and Jharkhand.(25) Personal hygiene practiced of hand washing after defecation, regular hand wash before eating and regular use of foot wears were significantly associated with lower infection. A similar finding was reported from a study in Kashmir.(29)

ACKNOWLEDGMENT: We acknowledged the co-operation offered by the study participants, Accredited Social Health Activists and Anganwadi workers without whom this would not have been possible

Funding: Nil

Conflict of interest: None declared

\section{REFERENCES:}

1. Bethony J, Brooker S, Albonico M, Geiger SM, Loukas A, Diemert D, Hotez PJ: Soil-transmitted helminth infections: ascariasis, trichuriasis, and hookworm. Lancet 2006; 367:1521-1532.

2. Brooker S, Clements ACA, Bundy DAP: Global epidemiology, ecology and control of soiltransmitted helminth infections. Adv Parasitol 2006; 62:221-261.

3. Hotez PJ, Molyneux DH, Fenwick A, Kumaresan J, Erlich Sachs S, Sachs JD, Savioli L: Control of neglected tropical diseases. N Engl J Med 2007; 357:1018-1027.

4. Hotez PJ, Brindley PJ, Bethony JM, King CH, Pearce EJ, Jacobson J: Helminth infections: the great neglected tropical diseases. J Clin Invest 2008; 118:1311-1321.

5. Worm infestation,www.newstodaynet.com (accessed on 16 th January, 2012)

6. Montresor A, Crompton DWT, Hall A, Bundy DA, Savioli L. Guidelines for the evaluation of soiltransmitted helminthiasis and schistosomiasis at a community level. World Health Organization, Geneva: 1998. WHO/CTD/SIP/ 98.1.

7. Chan MS, Medley G, Jamison D, Bundy DA. The evaluation of potential global morbidity attributable to intestinal nematode infections. Parasitology 1994;109:373-87.

8. King, C.H. Lifting the burden of schistosomiasis - defining elements of infection-associated disease and the benefits of anti-parasite treatment. J Infect Dis 2007; 196:653-655.

9. Bethony, J., et al. Soil-transmitted helminth infections: ascariasis, trichuriasis, and hookworm. Lancet 2006; 367:1521-1532.

10. Budke, C.M., Jiamin, Q., Qian, W., and Torgerson, P.R. Economic effects of echinococcosis in a disease-endemic region of the Tibetan Plateau. Am J Trop Med Hyg 2005; 73:2-10.

11. Flores A, Esteban JG, Angles R, Mascoma S. Soil transmitted helminth infections at very high altitude in Bolivia. Transaction of Royal Society of Tropical Medicine and Hygiene. 2011; 95:272-277. 


\section{ORIGINAL ARTICLE}

12. Arinola 0, Fawole O. Age and sex graded helminth infections in a Nigerian village. East African Medical Journal 1995; 72(2): 110-112.

13. Ejezie GC. The parasitic disease of school children in Lagos state, Nigeria. Acta Tropica. 1981; 38:79-84.

14. WHO Deworming for health \& development. Report of $3^{\text {rd }}$ global meeting of the partners for parasitic Central Geneva Switzerland, WH02005.

15. William Blangero. Attitudes towards helminthic infection in Jirel population of eastern Nepal, Social Science of Medicine, 1998 august, 47(3):371-9.

16. Filippo Curtale. Knowledge, Perception and Behaviour of mothers towards intestinal helminths in upper Egypt: Implication for control. Health policy and planning 13(4):423-432).

17. Acka CA, Raso G, N'Goran EK, Tschannen AB, Bogoch II, et al. (2010) Parasitic Worms: Knowledge, Attitudes, and Practices in Western $\mathrm{Co}^{\wedge}$ te d'Ivoire with Implications for Integrated Control. PLoS Negl Trop Dis 4(12): e910).

18. William Blangero. Attitudes towards helminthic infection in Jirel population of eastern Nepal. Social Science of Medicine. 1998 august; 47(3):371-9.

19. Johnston K. Courtright P. and Burnham G. Knowledge and attitudes toward onchocerciasis in the Thyolo highlands of Malawi. Trop Med Parasitol 1994; 45(4):3413.

20. Ovuga EB. Social and psychological aspects of onchocercal skin disease in Nebbi district, Uganda. East Afr Med J 1995; 72(7):449-53.

21. Edungbola LD. Cutaneous myiasis due to tumbu-fly, Cordylobia anthropophaga in Ilorin, Kwara State, Nigeria. Acta Tropica 1982; 39: 355-362.

22. WHO, Guidelines for the evaluation of Soil-transmitted helminthiasis and schistosomiasis at community level, WHO/CTD/SIP/98.1 WHO, Geneva; 1998.

23. Geerts $S$ and Gryseels B. Anthelmintic resistance in human helminths: a review. Trop Med Int Health 2001; 6(11):915-21.

24. Cioli D. Praziquantel: is there real resistance and are there alternatives? Curr Opinion Infect Dis. 2000; 13:1-5.

25. Awasthi S, Verma T, Kotecha P V, Venkatesh V, Joshi V, Roy S. Prevalence and risk factors associated with worm infestation in pre-school children (6-23 months) in selected blocks of Uttar Pradesh and Jharkhand, India. Indian J Med Sci 2008; 62:484-491.

26. M Bhattacharya, V Joon, V Jaiswal. Water Handling and Sanitation Practices in Rural Community of Madhya Pradesh: A Knowledge, Attitude and Practice Study. Indian J Prev Soc Med 2011; 42(1):94-97.

27. Natasha Saunders. Maternal Knowledge, attitudes and Practices concerning child health among mothers of children younger than 60 months in Kep District, Kingdom of Cambodia. Final Report 2005.

28. Showkat Ahmad Wani, Fayaz Ahmad, Showkat Ali Zargar, Ayesha Amin, Zubair Ahmad Dar, Pervaiz Ahmad Dar. Intestinal Helminthiasis in Children of Gurez Valley of Jammu and Kashmir State, India. J Glob Infect Dis 2010; 2(2): 91-94.

29. Wani SA, Ahmad F. Intestinal helminths and associated risk factors in children of district Pulwama, Kashmir, India. Indian Journal of Medical Microbiology 2009; 27(1):81-82. 


\begin{tabular}{|c|c|c|}
\hline Characteristics & Total $(n=117)$ & Percentage \\
\hline \multicolumn{3}{|l|}{ Type of Worms } \\
\hline Round worm & 22 & $19 \%$ \\
\hline Thread worm & 32 & $26.80 \%$ \\
\hline Tape worm & 3 & $2.60 \%$ \\
\hline No idea & 60 & $51.60 \%$ \\
\hline \multicolumn{3}{|l|}{ Symptoms of Worm infestation } \\
\hline Pain abdomen & 27 & $23 \%$ \\
\hline Pain abdomen and itching & 23 & $19.60 \%$ \\
\hline Perini itching & 23 & $19.60 \%$ \\
\hline Vomiting,worms in stool or worms coming through nose & 27 & $23 \%$ \\
\hline No idea & 17 & $14.80 \%$ \\
\hline \multicolumn{3}{|l|}{ Cause of Worm infestation } \\
\hline Eating food contaminated with soil. & 2 & $1.70 \%$ \\
\hline Eating with unwashed hands. & 12 & $10.30 \%$ \\
\hline Eating sugary foods. & 61 & $52.10 \%$ \\
\hline Eating with unwashed hands and sugary foods. & 12 & $10.30 \%$ \\
\hline Eating meats and sugary foods. & 13 & $11.10 \%$ \\
\hline No idea. & 17 & $14.50 \%$ \\
\hline \multicolumn{3}{|l|}{ Source of worm infestations } \\
\hline Animal feces & 04 & $3.4 \%$ \\
\hline Human feces & 23 & $19.6 \%$ \\
\hline Meat & 08 & $6.8 \%$ \\
\hline Soil & 15 & $12.8 \%$ \\
\hline Water & 10 & $8.5 \%$ \\
\hline Don't know & 29 & $24.8 \%$ \\
\hline Sugar & 28 & $23.9 \%$ \\
\hline
\end{tabular}

\section{Table 2: Mothers' practice on prevention of worm infection $(n=117)$}

\begin{tabular}{lcc}
\multicolumn{1}{c}{ Variables Characteristics } & Total $^{*}$ & Percentage (\%) \\
\hline Hand washing before eating and feedings & 76 & $64.96 \%$ \\
Hand washing after defecation of self and children & 68 & $58.12 \%$ \\
Regular use of foot wears by self and children & 67 & $57.27 \%$ \\
Food hygiene & 97 & $83.0 \%$ \\
Use of sanitary latrine & 47 & 40.17 \\
\hline
\end{tabular}

*multiple Response 


\begin{tabular}{|c|c|c|c|c|}
\hline \multirow{2}{*}{\multicolumn{2}{|c|}{ Variables determinants }} & \multicolumn{2}{|c|}{ Worms infestation } & \multirow{2}{*}{$P$ value } \\
\hline & & Present & Absent & \\
\hline \multirow{2}{*}{ Type of latrine } & Sanitary latrine & $10(8.55 \%)$ & $37(31.62 \%)$ & \multirow{2}{*}{0.000} \\
\hline & Insanitary latrine & $55(47.01 \%)$ & $15(12.82 \%)$ & \\
\hline \multirow{2}{*}{ Hand washing after defecation } & Yes & $24(20.51 \%)$ & $44(37.61 \%)$ & \multirow{2}{*}{0.000} \\
\hline & No & $39(33.33 \%)$ & $10(8.55 \%)$ & \\
\hline \multirow[t]{2}{*}{ Regular hand wash before meals } & Yes & $32(27.35 \%)$ & $44(37.61 \%)$ & \multirow{2}{*}{0.000} \\
\hline & No & $33(28.20 \%)$ & $8(6.84 \%)$ & \\
\hline \multirow[t]{2}{*}{ Regular use of foot wears } & Yes & $21(17.95 \%)$ & $46(39.32 \%)$ & \multirow{2}{*}{0.000} \\
\hline & No & $44(37.61 \%)$ & $6(5.12 \%)$ & \\
\hline
\end{tabular}

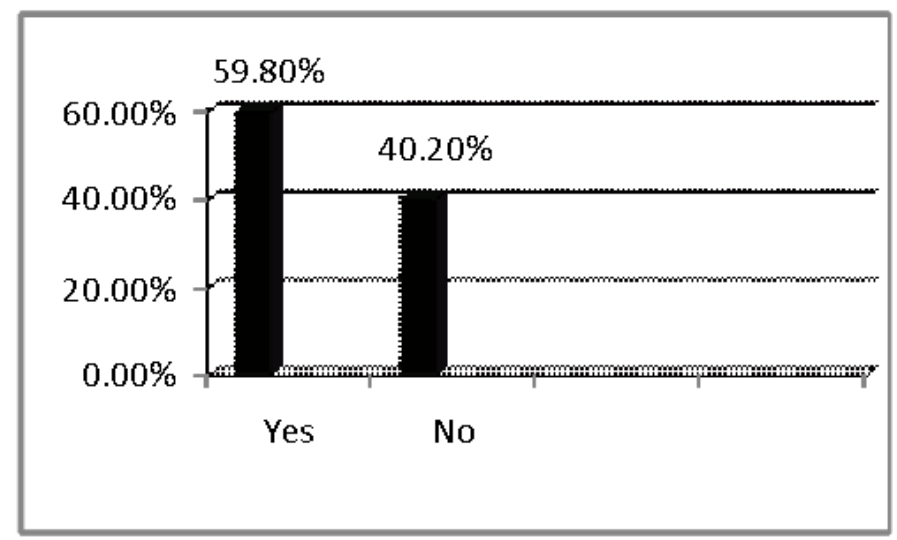

Fig. 1: Children treated with anthelminthic drug.

\section{AUTHORS:}

1. Amar Tripura

2. Taranga Reang

3. Kaushik Tripura

4. Arundhuti Roy

\section{PARTICULARS OF CONTRIBUTORS:}

1. Post Graduate Trainee, Department of Community Medicine, Agartala Government Medical College \& Govind Ballabh Pant Hospital, Agartala, Tripura.

2. Assistant Professor, Department of Community Medicine, Agartala Government Medical College \& Govind Ballabh Pant Hospital, Agartala, Tripura.

3. Post Graduate Trainee, Department of Community Medicine, Agartala Government Medical College \& Govind Ballabh Pant Hospital, Agartala, Tripura.
4. Tutor, Department of Community Medicine, Agartala Government Medical College \& Govind Ballabh Pant Hospital, Agartala, Tripura.

\section{NAME ADRRESS EMAIL ID OF THE CORRESPONDING AUTHOR:}

Dr. Amar Tripura,

Agartala Government Medical College \& Govind Ballabh Pant Hospital, Agartala, Tripura, PIN - 799006.

Email - amartripura@ymail.com

Date of Submission: 08/11/2013. Date of Peer Review: 09/11/2013. Date of Acceptance: 15/11/2013. Date of Publishing: 19/11/2013 